\title{
A LITERATURA NA SEÇÃO INFANTIL DA BIBLIOTECA PÚBLICA DO PARANÁ: A HORA DO CONTO
}

\author{
LITERATURE IN CHILDREN SECTION OF PARANÁ PUBLIC \\ LIBRARY: THE TALE TIME
}

\section{LITERATURA INFANTIL EN LA SECCIÓN DE BIBLIOTECA PÚBLICA DE PARANÁ: HORA DEL CUENTO}

\author{
Karina Valim de Araujo ${ }^{1}$ \\ Prefeitura Municipal de Pinhais, Pedagoga \\ Evelyn de Almeida Orlando ${ }^{2}$ \\ Pontifícia Universidade Católica do Paraná, Professora do Programa de Pós-graduação em \\ Educação
}

Resumo: Este artigo é resultado de um estudo realizado na "Hora do conto" da seção infantil da Biblioteca Pública do Paraná (BPP). Com o objetivo de analisar a formação do leitor ainda na infância, partiu-se da problemática de como a "Hora do conto" pode contribuir para tal formação. Utilizaram-se como instrumentos de pesquisa a observação e a análise de fotos, constituindo-se como registros documentais dentro de uma abordagem de pesquisa qualitativa. As principais referências teóricas foram: Arroyo (2008), Zilberman (2003), Abramovich (1995) e Chartier (1989, 2001). Os resultados indicam que as práticas educativas ocorrem de maneira lúdica e que a "Hora do conto" tornou o espaço um polo de encontro cultural, fomentando o interesse pela leitura que, por se realizar no âmbito de uma biblioteca, coloca as crianças em contato direto com o universo literário.

Palavras-chave: Literatura. Infância. Hora do conto.

Abstract: This article is the result of a study carried out in the "Tale time" of the children section of Paraná Public Library (BPP). With the objective of analyzing the re-

\footnotetext{
${ }^{1}$ Graduada em Pedagogia pela Pontifícia Universidade Católica do Paraná; mestranda em Educação pela Pontifícia Universidade Católica do Paraná.

2 Doutora em Educação pela Universidade do Estado do Rio de Janeiro; Mestre em Educação pela Universidade Federal de Sergipe.
} 
ader formation while in childhood, we start from the problematization on how BPP'S the "Tale time" can contribute to such formation. We used as research instruments the observation and analysis of photos as documentary records within a qualitative research approach. The main theoretical references were: Arroyo (2008), Zilberman (2003), Abramovich (1995) and Chartier (1989, 2001). The results indicate that the educational practices take place in a playful way and that the "Tale time" has become a space of cultural encounter, fomenting interest for the reading, which being realized in a library, puts the children in direct contact with the literary universe.

Keywords: Literature. Childhood. Tale time.

Resumen: Este artículo es el resultado de un estudio realizado en la "Hora del cuento" de la sección infantil de la Biblioteca Pública de Paraná (BPP). Con el objetivo de analizar la formación del lector en la infancia, partimos de la problemática de cómo la "Hora del cuento" de la BPP puede contribuir a tal formación. Utilizamos como instrumentos de investigación la observación y el análisis de fotos como registros documentales dentro de un enfoque de investigación cualitativa. Las principales referencias teóricas fueron: Arroyo (2008), Zilberman (2003), Abramovich (1995) y Chartier (1989, 2001). Los resultados indican que las prácticas educativas ocurren de manera lúdica y que la "Hora del cuento" se ha convertido en el espacio de encuentro cultural, fomentando el interés por la lectura que, por realizarse en el marco de una biblioteca, coloca a los niños en contacto directo con el universo literario.

Palabras clave: Literatura. La infancia. Hora del cuento.

\section{INTRODUÇÃO}

As pesquisas realizadas no campo da educação e leitura ${ }^{3}$ vêm chamando a atenção para a importância da literatura na infância, tanto para a formação do leitor quanto como ferramenta pedagógica que auxilia na reflexão sobre valores, de senso estético e crítico, imaginação, hábitos e comportamentos, acarretando conhecimentos próprios, além de currículos e denominações. A literatura pode proporcionar diversos ganhos ao desenvolvimento cognitivo na infância, e sua disponibilização em instituições de cunho educacional é de extrema relevância, pois ela é vista como uma arte formadora na cultura infantil.

\footnotetext{
${ }^{3}$ Destacamos aqui os trabalhos de Zilberman (2003), Arroyo (2008), Chartier (1989, 2001) e Abramovich (1995).
} 
O leitor, de acordo com Silva (2013, p. 187), “[...] esse aparente desconhecido, talvez seja o personagem que mais pista deixa pelos caminhos da história da leitura, se bem observadas." Dessa maneira, consideramos que a seção infantil da Biblioteca Pública do Paraná (BPP), um espaço não formal de educação, mostra-se como um campo relevante de pesquisa, pois nele encontramos respostas relativas ao gosto das crianças que, como leitores em formação, buscam a literatura fora da escola.

Diante disso, esta pesquisa seguiu uma abordagem qualitativa que, para Ludke e André (1986, p. 18), “[...] se desenvolve numa situação natural, é rica em dados descritivos, tem um plano aberto e flexível e focaliza a realidade de forma complexa e contextualizada." Apesar disso, ela é de natureza básica, explicativa e se classifica, ainda do ponto de vista metodológico, como uma pesquisa de campo. Para Gil (2008, p. 57),

\begin{abstract}
Os estudos de campo procuram muito mais o aprofundamento das questões propostas [...] Como consequência, o planejamento do estudo de campo apresenta maior flexibilidade, podendo ocorrer mesmo que seus objetivos sejam reformulados ao longo do processo de pesquisa. Outra distinção é a de que no estudo de campo estuda-se um único grupo ou comunidade em termos de sua estrutura social, ou seja, ressaltando a interação de seus componentes. Assim, o estudo de campo tende a utilizar muito mais técnicas de observação do que de interrogação.
\end{abstract}

Os sujeitos envolvidos foram, de maneira indireta, os leitores/frequentadores da seção infantil da BPP e, de forma direta, os mediadores e contadores de história que trabalham nesse espaço. Para alcançar o objetivo de analisar a formação do leitor ainda na infância, utilizamos como procedimentos a observação e a análise documental (com as fotografias que são entendidas como documentos). Para o planejamento da coleta de dados, tivemos como base a seguinte problemática: como a "Hora do conto" da BPP pode contribuir para a formação do leitor ainda na infância?

Assim, como procedimento para a reunião de dados, primeiramente realizamos uma seleção de fotografias contemplando as referências visuais possíveis ao visitante, os espaços que propiciam a exploração de atividades, a disposição dos livros, bem como a de outros recursos destinados a diferentes atividades. Ademais, verificamos o fluxo e os interesses dos visitantes, como os empréstimos, a fim de percebermos como ocorre a exploração dos espaços pelas crianças e de que maneira é a interferência dos adultos. De modo específico, observamos na "Hora do conto": a média de ouvintes, sua idade, quem eram os acompanhantes das crianças, qual a liberdade do visitante em interferir ou realizar perguntas e como é a reação das crianças ao escutar uma nova história. 
Historicamente, a utilização da literatura como metodologia para a leitura diversas vezes desviou o encantamento das crianças pelo livro. Tal prática deve fomentar o prazer pelo próprio ato de ler, e, caso seja feito o contrário, é alto o risco em criar uma resistência à leitura por acabar com algo que lhe é preliminar: o gostar. Até hoje, conforme Zilberman (2003 p. 16), “[...] a literatura infantil permanece como colônia da pedagogia, o que lhe causa grandes prejuízos: não é aceita como arte, por ter uma finalidade pragmática; e a presença do objeto didático faz com que ela participe de uma atividade comprometida com a dominação da criança."

Desse modo, a literatura para a infância deve satisfazer o gosto do leitor, não o do professor e, muito menos, prevalecer um conteúdo. A história da rejeição pelo ato de ler mostra que a utilização da literatura como método para alcançar outros objetivos é prejudicial, pois, se o aluno não gostar do contexto apresentado, poderá não se interessar pela literatura, criando, assim, uma barreira para os textos literários e reduzindo seu repertório de leitura.

Nesse contexto, para a formação literária ainda na infância é necessário compreender a criança como o sujeito principal da perspectiva, na qual sejam prevalecidas as suas particularidades. De acordo com Arroyo (2008, p. 121), o "[...] pensamento educativo não se constrói nem se repensa se esquecer da infância e adolescência, se esquecer dos tempos humanos com que trabalha, se não as crianças, adolescentes viram apenas alunos em séries e anos letivos." Torna-se imperativo, portanto, superar a visão do sujeito como apenas um aluno, e da leitura como uma decodificação para outros fins. A literatura é um caminho possível para a constituição do leitor, seja ele criança ou não. Como afirma Silva (2010, p. 58), a "[...] leitura e a literatura têm suas determinações histórico-sociais, mas, dialeticamente, podem provocar rupturas, movimentos de emancipação."

Pensar a formação do leitor vai além de pensar no domínio específico da leitura. Essa reflexão implica entender, conjuntamente, os sentidos sociais e culturais que estão imbricados nessa prática. "A partir deste terreno de trabalho em que se enredam o texto, o livro e a leitura, podem-se formular várias proposições que articulam de maneira nova os recortes sociais e as práticas culturais.” (CHARTIER, 1989, p. 182).

Diante de tais apontamentos, pensar a literatura como objeto de pesquisa justifica-se pelo fato de a formação literária ter uma função primordial dentro do processo de formação do indivíduo. O local escolhido para esta pesquisa não foi uma biblioteca escolar, mas uma seção da Biblioteca Pública do Paraná que promove atividades específicas e regulares voltadas ao público infantil, como a contação de histórias, no sentido de estimular a prática da leitura e criar uma aproximação desse 
público com a biblioteca e o mundo dos livros. Essa experiência extraescolar permite uma possibilidade de contato com a literatura muito mais pela arte e pela cultura do que pela educação formal, como acontece frequentemente nas bibliotecas escolares, o que não diminui a sua dimensão formativa.

Pensar a biblioteca como um espaço de difusão da leitura já vem sendo um investimento de alguns pesquisadores. Grande parte ainda mantém como local privilegiado da pesquisa a biblioteca escolar, como o livro clássico As bibliotecas escolares: entre leitura pública e leitura escolar na França do II Império e da III República, de Jean Hèbrard (1991); o livro Biblioteca escolar e práticas educativas: o mediador em formação, organizado por Souza (2009); Biblioteca escolar e a formação de leitores: o papel do mediador de leitura, organizado por Silva (2009); e a dissertação de Léia Anny de Oliveira Moraes (2014), intitulada Leitura e mediação: concepções de professores que atuam em bibliotecas escolares. Já a dissertação Experiências de leituras de crianças em diferentes contextos, de Andrea Del Larovere (2014), discute tanto os espaços escolares quanto os públicos, expandindo seus olhares para os ambientes extraescolares. Há também um artigo relevante para o resgate dessa temática no Brasil, de autoria de Rovilson José da Silva (2009), chamado Leitura, Biblioteca e política e formação de leitores no Brasil. Em uma perspectiva internacional, Gisele Reis (2014), em Leitura para os pequenos: uma experiência em San Miniato, reflete o trato com a leitura que, independente do espaço, tem como objetivo a formação de leitores. Tais trabalhos são apenas indicativos do investimento que vem sendo feito por diferentes pesquisadores em relação a esses espaços de leitura, uma vez que essa temática vem mobilizando um conjunto expressivo de pesquisadores da área.

Nesse movimento, é importante destacar o crescimento do Congresso de Leitura (COLE), organizado pela Associação de Leitura do Brasil, que completou sua $20^{\mathrm{a}}$ edição em 2016. Realizado a cada dois anos na Unicamp, esse Congresso apresenta-se como um espaço relevante para a área por reunir pesquisadores interessados em problemáticas voltadas para a formação do leitor, as práticas de leitura, os usos da literatura em diferentes contextos e espaços e a própria produção de livros e materiais de leitura.

Já é consensual entre os pesquisadores da área a potencialidade da literatura na formação social e cultural da criança. "Sua atuação dá-se dentro de uma faixa de conhecimento, não porque transmite informações e conhecimentos morais, mas porque pode outorgar ao leitor a possibilidade de desdobramento de suas capacidades intelectuais.” (ZILBERMAN, 2003, p. 46). Essas capacidades são estimuladas no sentido de ampliar o potencial de leitura em suas diferentes formas. $\mathrm{O}$ trabalho que 
identificamos na BPP acaba desenvolvendo, ainda, uma multiplicidade de leitores. $\mathrm{Na}$ contação, todos são leitores a seu modo e em diferentes tempos; eles mergulham no universo da literatura e reinventam para si e para o outro uma multiplicidade de leituras possíveis e imagináveis do texto e do mundo.

\section{A SEÇÃo INFANTIL DA BIBLIOTECA PÚBLICA DO PARANÁ}

A fundação da Biblioteca Pública do Paraná ocorreu em 07 de março de 1857; em 1954 e em 1993 ela passou por algumas reformas. No ano 1961, a BPP recebeu da Comissão Estadual de Bibliotecas do Estado do Guanabara o Prêmio Paula Brito, por se apresentar como uma biblioteca modelo e instituição padrão de desenvolvimento e difusão cultural do Brasil. Em relação à seção infantil, não foi possível determinar uma data exata de sua criação, mas sabemos que existe, pelo menos, desde 1992 (BIBLIOTECA PÚBLICA DO PARANÁ, 2017).

Fotografia 1 - Seção infantil da BPP em 1992

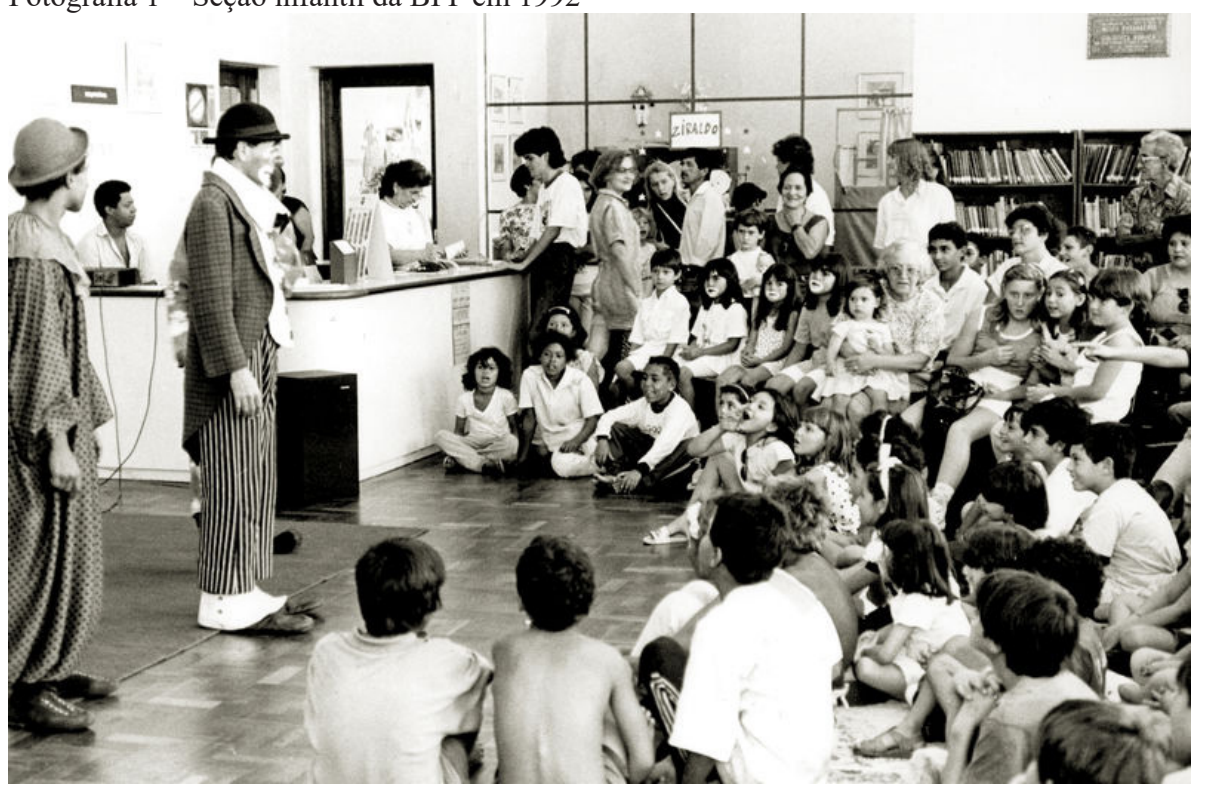

Fonte: Biblioteca Pública do Paraná (2017).

A história das bibliotecas no Brasil se assemelha com a história do livro e a da leitura. Para Silva (2009, p. 79), o “[...] surgimento das bibliotecas possibilitou que não só a burguesia tivesse acesso à leitura, mas que outros segmentos sociais também pudessem desfrutar dela." Entre o fim do século XIX e início do XX, o acesso a esse 
tipo de cultura foi cada vez mais expandido, e a criação das bibliotecas muito contribuiu com esse cenário. Segundo Milanesi (1993), em 1936 criou-se uma proposta de biblioteca infantil, entre outras categorias, porém, logo foi desativada. De acordo com Silva (2009), essas propostas nem sempre se efetivaram porque havia a falta de incentivo do Estado Novo.

Hoje, as bibliotecas constituem-se ambientes para leituras e empréstimos de livros com objetivos diversos e estão localizadas dentro de escolas, em espaços culturais e/ou educativos. No entanto, a história dessas bibliotecas como espaço cultural é bem recente. Antes, o ensino e a pesquisa escolar eram o centro desses espaços. Segundo Monteiro (2012, p. 11),

A partir de meados da década de 1990, o ensino sofreu grandes mudanças, e os governos passaram a comprar livros didáticos e a distribuí-los entre os alunos. E, com a popularização da internet, entre 1996 e 1997, abriram-se outras possibilidades para a pesquisa escolar. [...] Frente a isso, as bibliotecas passaram por uma crise de identidade. Deixaram de ser bibliotecas escolares para ser efetivamente bibliotecas públicas.

Essas mudanças favoreceram, sobremaneira, a formação de novos leitores e a frequência às bibliotecas. Para Monteiro (2012, p. 9), "“...] a partir das décadas de 1980 e 1990, começou a discussão sobre políticas de leitura, como leitura acessível a todos, em que as bibliotecas públicas eram um elemento fundamental." A biblioteca escolar, nesse cenário, também foi revista e atualizada. Conforme Silva (2009, p. 79), a "[...] implantação das bibliotecas escolares e da Hora do conto contribui para uma maior circulação de materiais impressos."

É perceptível que as bibliotecas escolares, nesse contexto, precisaram recorrer a propostas pedagógicas que considerassem a literatura uma formativa cultural, social e de identidade. Para Arroyo (2008, p. 119), estamos presenciando “[...] tempos em que o pensamento pedagógico é levado a rever suas verdades, metáforas e auto-imagens, a partir das experiências da infância." Ou seja, a literatura pode se incluir nessa revisão, a qual considera a criança um leitor em potencial.

Para repensarmos a importância da biblioteca, devemos analisar como e para que os alunos a utilizam. De acordo com Abramovich (1995, p. 163), “[...] a ida à biblioteca está incluída nas opções de programação escolar e extracurricular da criança? E nas de lazer? Tão pouco e tão raramente [...] E uma biblioteca é um centro de descobertas [...]" Portanto, para que a biblioteca garanta um processo formativo de leitores literários, deve ter um fluxo constante, ora programado, ora por escolha própria das crianças. 
A seção infantil é um espaço localizado no interior da Biblioteca Pública do Paraná e reúne diversos títulos infanto-juvenis para empréstimo e leitura local. Há também alguns momentos de contação de história e produção artística a partir de leituras. Apesar da prática de a contação de histórias ser o objeto deste artigo, é preciso situá-la nesse cenário.

Fotografia 2 - Seção infantil da BPP

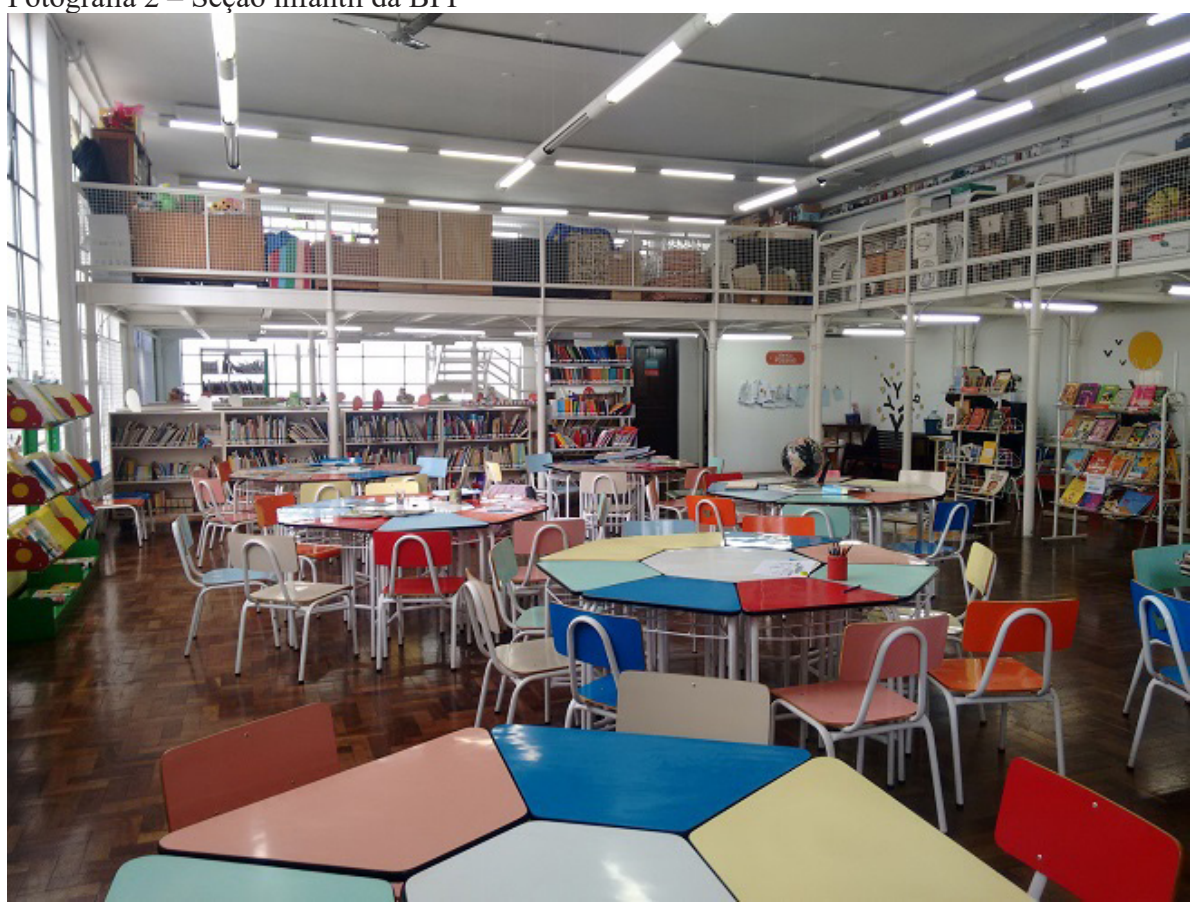

Fonte: os autores.

A seção infantil da BPP é composta por diferentes espaços, a saber: estantes de livros, que contemplam divisões por idade, clássicos, sugestões e língua estrangeira; a Gibiteca, uma sala com gibis e mesas com tabuleiros de xadrez; o Telecentro, com três computadores e acesso à internet; o Varal de poesias, onde são expostas pinturas e poesias; a Oficina, um andar superior com mesas e materiais para produções artísticas; o centro do espaço, onde ficam diversas mesas; e a sala da "Hora do conto". A seção infantil da BPP existe há alguns anos e demonstra uma intenção diferenciada de formação do leitor que concebe o próprio espaço como um estímulo à prática de leitura. 
$\mathrm{O}$ ato de ler, prática comum do nosso cotidiano, possui sentidos que vão além da decifração dos códigos escritos. Segundo Chartier (1989, p. 181), a “[...] leitura não é somente uma operação abstrata de intelecção: é pôr em jogo o corpo, é inscrição num espaço, relação consigo ou com o outro."

Para alguns, a leitura literária é reconhecida apenas como algo benéfico, pois permite acessar um conjunto de informações que são veiculadas cotidianamente pela escrita. Para outros, é vista como uma parte cultural integrante da arte. Monteiro (2012, p. 13) a define da seguinte forma: "Em particular, a literatura é disparadora de novos modos de pensar e inventar a própria existência, contra os modos hegemônicos de ser e de viver, com caminhos já determinados, sem possibilidade de criação ou cidadania."

Sendo parte integral da formação pessoal do cidadão e de sua cultura, é fundamental que se atente para os espaços que contemplam, de forma efetiva, a relação do sujeito com os livros. Tal compreensão coloca em evidência a produção desses espaços tanto na prática de leitura quanto como objeto de estudo privilegiado que permite compreender os múltiplos processos de formação do leitor.

Nesse sentido, o campo de pesquisa traz diversos espaços que privilegiam a participação do sujeito, até mesmo mediante outras atividades, buscando uma relação próxima com os livros, os quais aparecem dispostos para empréstimos ou para consulta local. É válido destacar a relação dos mediadores que, apesar de estarem sempre presentes, permitem o livre trânsito da criança naquele espaço, auxiliando apenas quando solicitados. A única restrição que aparece de forma mais incisiva e por escrito é a de não colocar os livros novamente na estante, o que é uma norma em qualquer biblioteca, independente da faixa etária do público.

Esse contato entre leitor e livro por meio de uma biblioteca viva, que proporciona ricas experiências literárias, é perceptível na BPP em razão de ela dispor de um espaço com atividades especificamente destinadas às crianças, o que de fato tem uma relação direta com a formação do sujeito leitor, como propõe o Parâmetro Curricular Nacional para a Língua Portuguesa do Ensino Fundamental:

Formar leitores é algo que requer, portanto, condições favoráveis para a prática de leitura - que não se restringem apenas aos recursos materiais disponíveis, pois, na verdade, o uso que se faz dos livros e demais materiais impressos é o aspecto mais determinante para o desenvolvimento da prática e do gosto pela leitura. (BRASIL, 1998, p. 44).

A formação de um espaço criativo e estimulante destinado à leitura é uma estratégia que incide diretamente nesse aspecto, possibilitando o desenvolvimento do interesse pela leitura. Nesse caminho, uma questão favorável observada no campo 
de pesquisa são indicações expostas, exemplificadas na Fotografia 3, pela diferente disposição de alguns livros para leituras iniciais. Títulos diversos, formatos diferentes, cores vibrantes, mas, sobretudo, os livros com as capas voltadas para a frente atraem a atenção do potencial leitor que pode manipular todos os livros dispostos na estante e explorar quais podem ser as suas possíveis preferências.

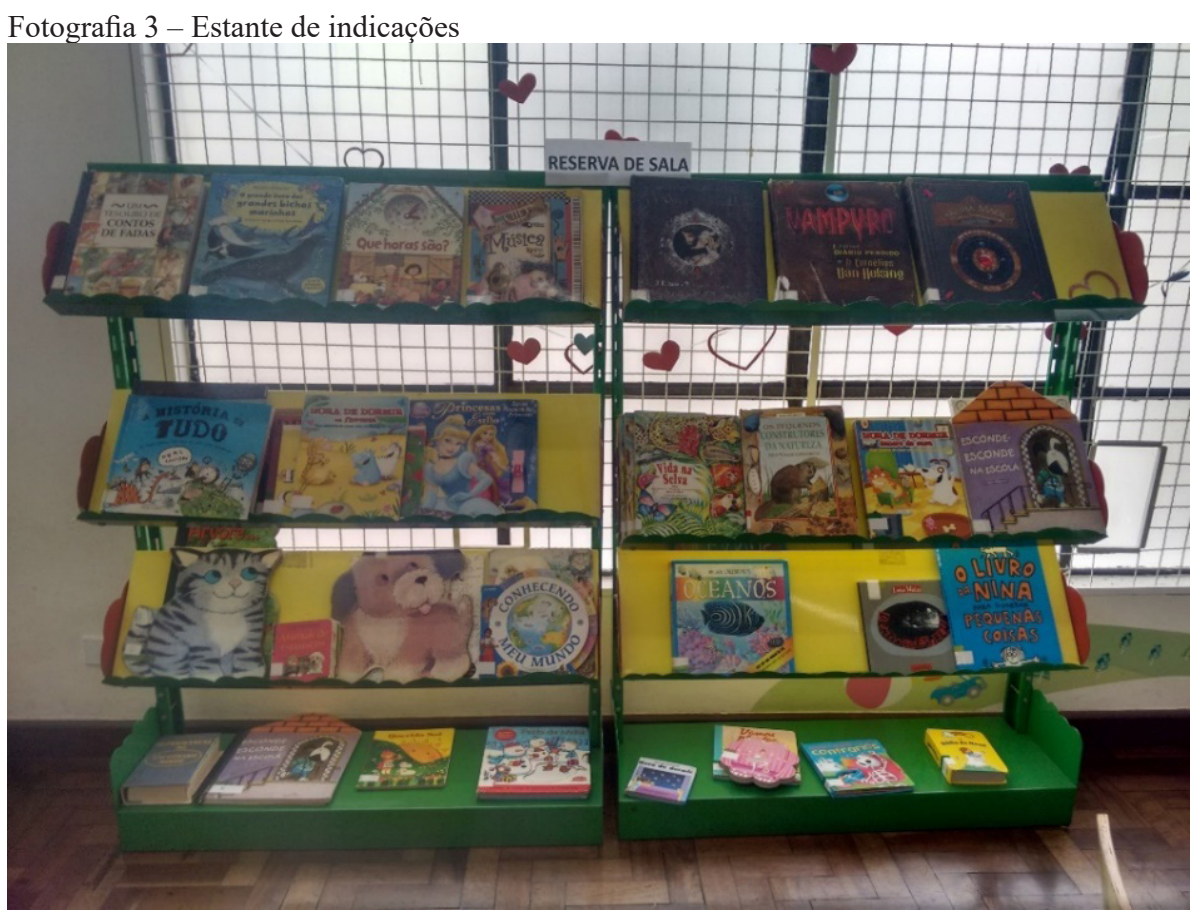

Fonte: os autores.

Em uma fase como a infância, na qual o desenvolvimento é constante, visitas às bibliotecas tornam-se relevantes. Assim, a criança pode encontrar respostas à sua identidade. Isso porque a "[...] biblioteca pode e deve ser uma grande aliada nesse momento, ainda que muitas pessoas a vejam como simples depósito de livros." (MARANGON, 2010, p. 44). Nessa questão de identidade, um tema que aparece exposto em diferentes livros "sugeridos" em estantes da seção infantil da BPP é a história africana e a relação com os afrodescendentes. É possível depreender, por meio dessa seleção de títulos, a busca pela produção de sentidos, sensibilidades e identidades por meio da leitura. A literatura, para além do deleite e do entretenimento, é potencialmente educativa para cada indivíduo dentro de suas perspectivas, e tal função não passa despercebida no Projeto Pedagógico da BPP. 
É necessário que todas as bibliotecas efetivem mudanças individuais e sociais, e o primeiro passo é o interesse dos leitores. "Para se montar uma biblioteca, qualquer que seja seu tamanho, começa-se indo às livrarias, onde se forma uma ideia do que existe, do que acabou de ser lançado, do que está circulando há tempo." (ABRAMOVICH, 1995, p. 150). Portanto, é sugestivo que esse espaço se exponha como um polo cultural, portador de uma identidade artística, na qual se coloca a literatura em foco para desenvolvimentos peculiares a cada sujeito a partir de sua exploração literária reflexiva.

\section{A INFÂNCIA NA BIBLIOTECA}

Bibliotecas sempre foram consideradas espaços para pesquisas, nos quais o silêncio é primordial para o seu funcionamento, fato extremamente opressor à personalidade da criança. Diante da necessidade de agregar leitores para efetivação de bibliotecas vivas, essa situação vem mudando de maneira geral. Para as crianças entrarem em uma biblioteca, a supervisão quase imobilizante sempre foi um fato; em razão do cuidado com os livros e da escolha do "título certo", o controle de sua autonomia e da leitura essencial sempre passaram por um olhar adultocêntrico. Monteiro (2012, p. 10 , grifo do autor) relata que "[...] as salas de 'pesquisa' eram os maiores espaços das bibliotecas e com mais títulos e exemplares."

A própria literatura já foi vista pela sociedade como algo exclusivamente sério, que necessita de concentração e com uma única função - a educativa -, que sempre ensinaria a criança a ser melhor segundo a perspectiva moral da sociedade. Silva (2010, p. 50) destaca que a "[...] disciplina e os valores pedagógicos conformaram o gênero de maneira tão vigorosa que, mesmo na modernidade, a literatura infantil não conseguiu desatrelar-se totalmente de uma feição educativa e moralizante."

A literatura infantil e as bibliotecas passam por um processo de modificação a partir de uma nova visão, na qual se procura agregar atrativos ao público-alvo. Como relata Silva (2010, p. 58): “A criança não é mera consumidora de cultura; ao contrário, está historica e socialmente inserida nessa cultura, sendo também um sujeito que a produz." Portanto, o investimento nessa área se torna cada vez mais urgente, pois as bibliotecas também possuem a função de produção cultural.

Colocando a criança, dentro de suas especificidades, no centro do processo e, consequentemente, dos seus objetivos, a seção infantil da BPP demonstra, em seu espaço e programação, o estímulo ao lúdico, ou seja, dispõe de ações que atraem o público infantil. Um exemplo que podemos verificar está na Fotografia 4, que retrata a 
amarelinha. No chão da seção, mostra-se à criança que a literatura pode ser associada a um momento leve e prazeroso, no qual uma brincadeira pode ser realizada entre uma leitura e outra.

Fotografia 4 - Amarelinha na Biblioteca - diálogo com a infância

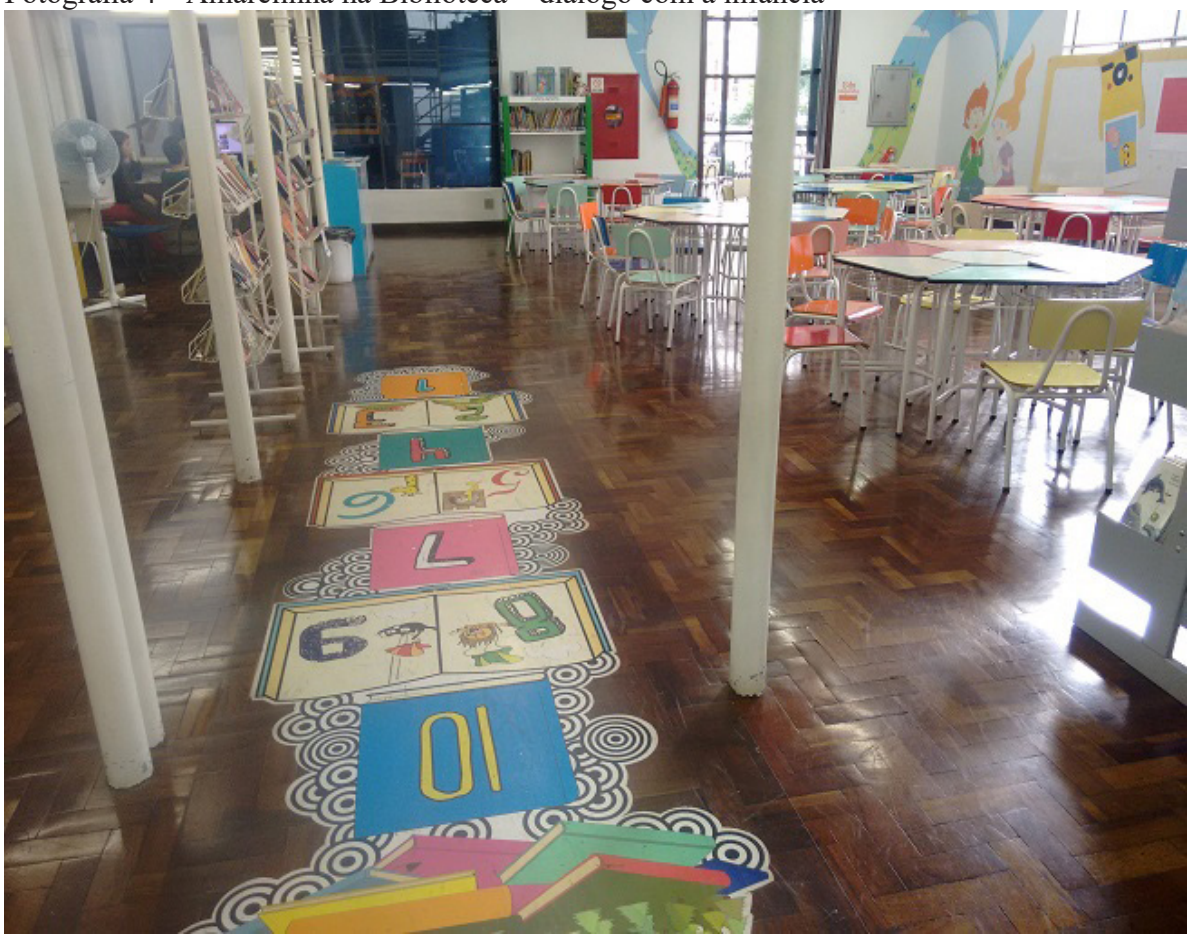

Fonte: os autores.

A infância começa a ganhar espaço em qualquer biblioteca a partir de uma literatura destinada à criança. Para Zilberman (2003, p. 66), compreendendo “[...] tudo o que é produzido para pessoas de até mais ou menos 12 anos, a literatura infantil deve ir se modificando à medida que evolui a criança [...]" Portanto, é necessário rever o que lhe é proporcionado e se está de acordo com seus anseios próprios, pois, como relata Abramovich (1995, p. 17), a literatura permite, também,

[...] ficar sabendo história, geografia, filosofia, política, sociologia, sem precisar saber o nome disso tudo e muito menos achar que tem cara de aula [...] Porque, se tiver, deixa de ser literatura, deixa de ser prazer e passa a ser didática, que é outro departamento (não tão preocupado em abrir as portas da compreensão do mundo). 
Considerando os diversos elementos característicos da infância, as bibliotecas podem se ater, cada vez mais, a elementos que consideramos um dos principais: a imaginação e/ou fantasia. Para Zilberman (2003, p. 49),

[...] não se pode escamotear a circunstância de que a fantasia é um importante subsídio para a compreensão de mundo por parte da criança: ela ocupa as lacunas que necessariamente se tem durante a infância, devido ao seu desconhecimento do real; ajuda-o a ordenar suas novas experiências, frequentemente fornecidas pelos próprios livros.

Para Marangon (2010, p. 46), a biblioteca “[...] deve propiciar ouvir e contar histórias, brincar com jogos educativos e recreativos [...] e ter uma seção de arte que estimule a pintura, a escultura e os desenhos." Nesse sentido, a seção infantil da $\mathrm{BPP}$ proporciona às crianças algumas oficinas, como podemos ver na Fotografia 5, sempre ligadas à "Hora do conto".

\section{Fotografia 5 - Oficina de arte}

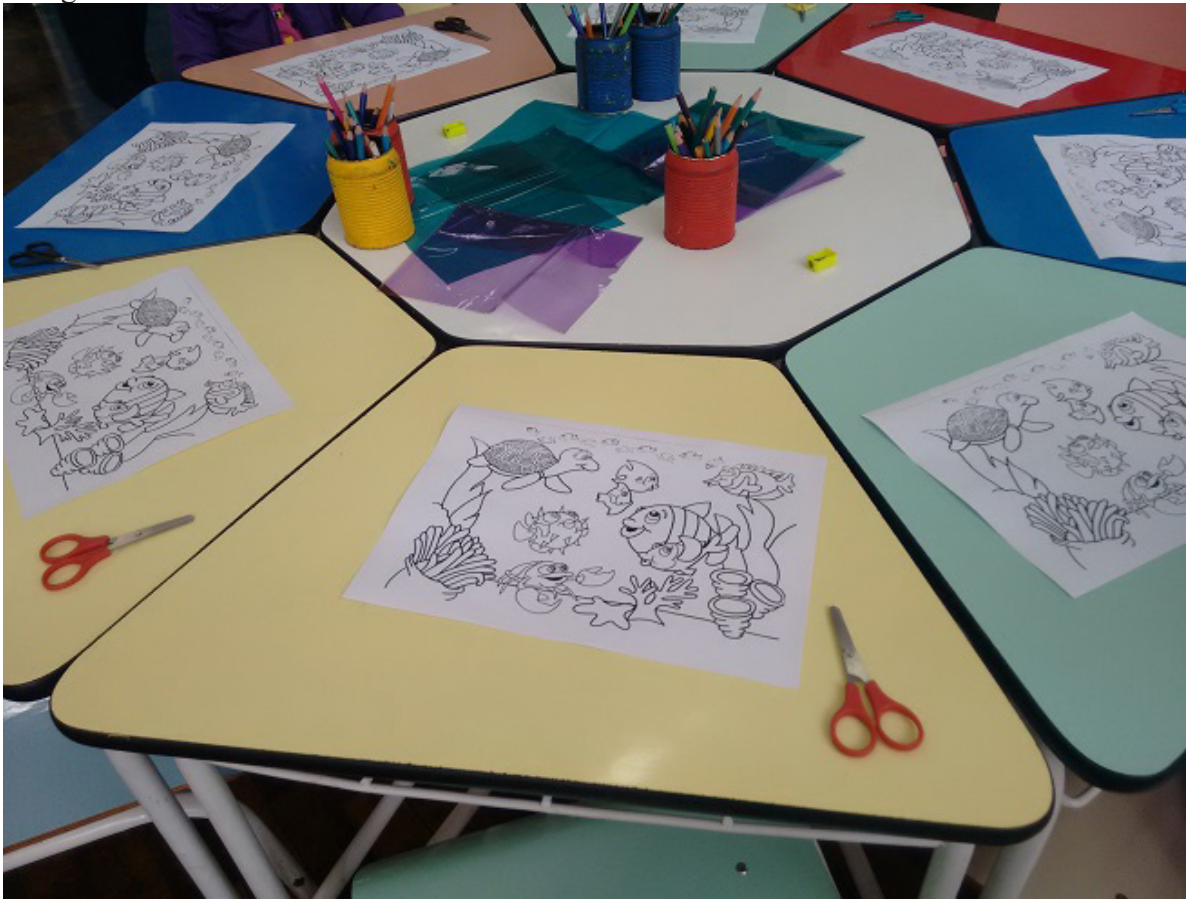

Fonte: os autores.

Esses são modos de mediações para o estímulo à leitura. Além disso, as crianças devem ser bem-vindas nas bibliotecas, sozinhas ou não, pois é necessária a 
participação delas como sujeitos do ato de ler, bem como a sua opção de escolha e curiosidade. Nesse caso, concordamos com a indagação de Abramovich (1995, p. 140):

Por que não ampliar os horizontes, indo às livrarias ou bibliotecas e deixando cada aluno manusear, folhear, buscar, achar, separar, repensar, rever, reescolher, até se decidir por aquele volume, aquele autor, aquele gênero, gênero, que naquele determinado dia, lhe desperta a curiosidade, a vontade, a inquietação???

Ao observar como é explorado o espaço pelas crianças na seção infantil da BPP, percebe-se que a mediação geralmente é atribuída aos pais, que, quando precisam de ajuda, solicitam aos mediadores e são atendidos. Quando há visita escolar, esses mediadores apresentam todos os espaços e possibilidades de atividades, além de deixarem que as crianças os explorem da maneira que lhes for mais agradável. No primeiro contato das crianças com a seção infantil da BPP, em razão das várias possibilidades atrativas nesse período da vida, é percebido que elas querem realizar todas as atividades, mas é de acordo com os gostos individuais que as escolhem, assim como quando encontram um livro relacionado ao tema que gostam e se prendem à leitura.

\section{HORA DO CONTO}

A formação do leitor pela literatura possui vários mecanismos pedagógicos relacionados aos modos distintos de apresentar o texto a ele. Isso inclui os vários modos de expor as histórias, da oralidade à estrutura textual até as ilustrações. De acordo com as Diretrizes Curriculares Municipais de Educação Infantil de Curitiba, “[...] os assuntos de trabalho com as crianças são os mais variados possíveis, sendo valorizados seus interesses, curiosidades, ou o que é próprio da infância." (CURITIBA, 2012, p. 7). Para Abramovich (1995, p. 17), temos sempre que ler histórias para as crianças, pois, com isso, será possível “[...] sorrir, rir, gargalhar com situações vividas pelas personagens, com a ideia do conto ou com o jeito de escrever dum autor e, então, pode ser um pouco cúmplice desse momento de humor, de brincadeira, de divertimento."

$\mathrm{E}$, mediante a vantagem do prazer artístico, configuram-se diferentes elementos à literatura. Assim, a biblioteca deixa de ser monótona para abrir portas ao lúdico. "A biblioteca precisa ser dinâmica, buscar estratégias que atraiam tanto as crianças quanto os professores e funcionários da escola." (MARANGON, 2010, p. 46). Um mecanismo expressamente funcional e quisto na infância é a hora do conto ou a contação de história, entendida aqui como uma prática de leitura mediada. Segundo Carvalho (2005, p. 94), 
A mediação de leitura é realizada em um determinado espaço físico, organizado e preparado para se tornar um local agradável, onde as crianças se sintam confortáveis e à vontade [...] Sempre que o mediador estende o tapete ou o lençol e coloca sobre ele os livros e as almofadas, as crianças passam a entender o significado desse momento, pois o ambiente fica mais aconchegante, e elas associam a hora da leitura com uma situação informal e agradável.

Além do ambiente favorável, a narrativa tem um papel fundamental e abrange tanto a técnica quanto o envolvimento com a história. Como relata Busatto (2001, p. 49), "Por contar com o coração, quero dizer também que acredito numa educação onde está presente o afeto e não apenas o impulso profissional em repassar conhecimentos, visando à formação técnica do ser humano." Na seção infantil da BPP, a "Hora do conto" acontece em dois horários: às $11 \mathrm{~h}$ e às $15 \mathrm{~h}$, de segunda-feira a sábado. Além disso, ela possui um espaço próprio, como podemos observar na Fotografia 6 .

Fotografia 6 - Espaço destinado à "Hora do conto"



Fonte: os autores. 
Sentimos que esse é o espaço mais aconchegante da Biblioteca. Ele possui um tapete personalizado, muitas almofadas, televisão, dvd, plotagens nas paredes e um palco de teatro de fantoches, além de conter duas portas de entrada e paredes de vidros, pelas quais é possível observar, para quem chega à seção infantil da BPP, as histórias ali contadas. O cuidado com o planejamento e a manutenção desse espaço é indicativo do lugar que a "Hora do conto" possui nessa seção da Biblioteca, considerada pelos funcionários como "carro-chefe".

Por meio da observação, constatamos que as contações de história são bem dinâmicas. As crianças têm liberdade para interferir ou realizar perguntas, proporcionando, com isso, que se crie uma intimidade delas com o texto, a partir da interação com a prática de leitura. Essa interação também pôde ser observada em uma situação específica, quando o cenário caiu e uma criança ajudou a reestruturá-lo.

A boa disposição dos contadores também é digna de nota. Quando as crianças acham algo engraçado, elas pedem para os contadores repetirem, e eles não se esquivam em fazer isso, mostrando que não aceleram a história a fim de logo terminá-la. Para Silva (1990, p. 14), esse momento exige uma dedicação na fala: "A linguagem deve ser correta, de bom gosto, simples, sem ser vulgar nem rebuscada. Os recursos onomatopaicos e as repetições contribuem para tornar a história mais interessante e dão mais força às expressões." Nesse encantamento, é importante também que o contador de histórias tenha atenção para a utilização correta do texto, de forma atraente. Como cita Abramovich (1995, p. 21),

[...] é bom que quem esteja contando crie todo um clima de envolvimento de encanto [...] Que saiba dar as pausas, criar os intervalos, respeitar o tempo para o imaginário de cada criança construir seu cenário, visualizar seus monstros, criar seus dragões, adentrar pela casa, vestir a princesa, pensar na cara do padre, sentir o galope do cavalo, imaginar o tamanho do bandido e outras coisas mais.

Ao observar a "Hora do conto" na seção infantil da BPP, bem como as pessoas envolvidas e suas ações, percebemos que, geralmente, são três contadores e, no máximo, seis personagens, sempre com um narrador. As histórias são contadas por meio da modalidade de teatro, empregando, na maioria das vezes, o fantoche. As vozes são utilizadas também como um recurso, tendo cada contador uma característica diferente, mas todos exploram, de maneira distinta, a sua voz, principalmente com as onomatopeias. As repetições eram constantes, pois as crianças frequentemente as solicitavam. Para Carvalho (2005, p. 44), 
A criança pede para repetir a mesma história porque experimentou emoções (como tristeza, alegria, medo) ao ouvi-la e a repetição lhe propicia brincar com essas situações em seu imaginário, pois está protegida pelo contexto do livro, pela companhia do mediador e tem o conforto da configuração da narrativa (conhece o desenvolvimento e o final da história).

A leitura de textos literários, nesse contexto, utiliza-se de elementos e locais atraentes, distanciando-se daquele momento de obrigatoriedade de leitura, além de estimular o ato de ler por esse tipo de exposição que é a "Hora do conto". "A ideia não é apresentar a leitura como ferramenta para aprender, mas como algo lúdico e capaz de encantar e divertir - a aprendizagem, nesse caso, passa a ser um delicioso efeito colateral!" (ROJAS, 2010, p. 3). Nessas ações da biblioteca estudada, as histórias tornavam-se tão atraentes que os encontros viravam referência para outros encontros, principalmente aos sábados, entre crianças de diferentes idades e seus familiares.

\section{Fotografia 7 - "Hora do conto" em um sábado}

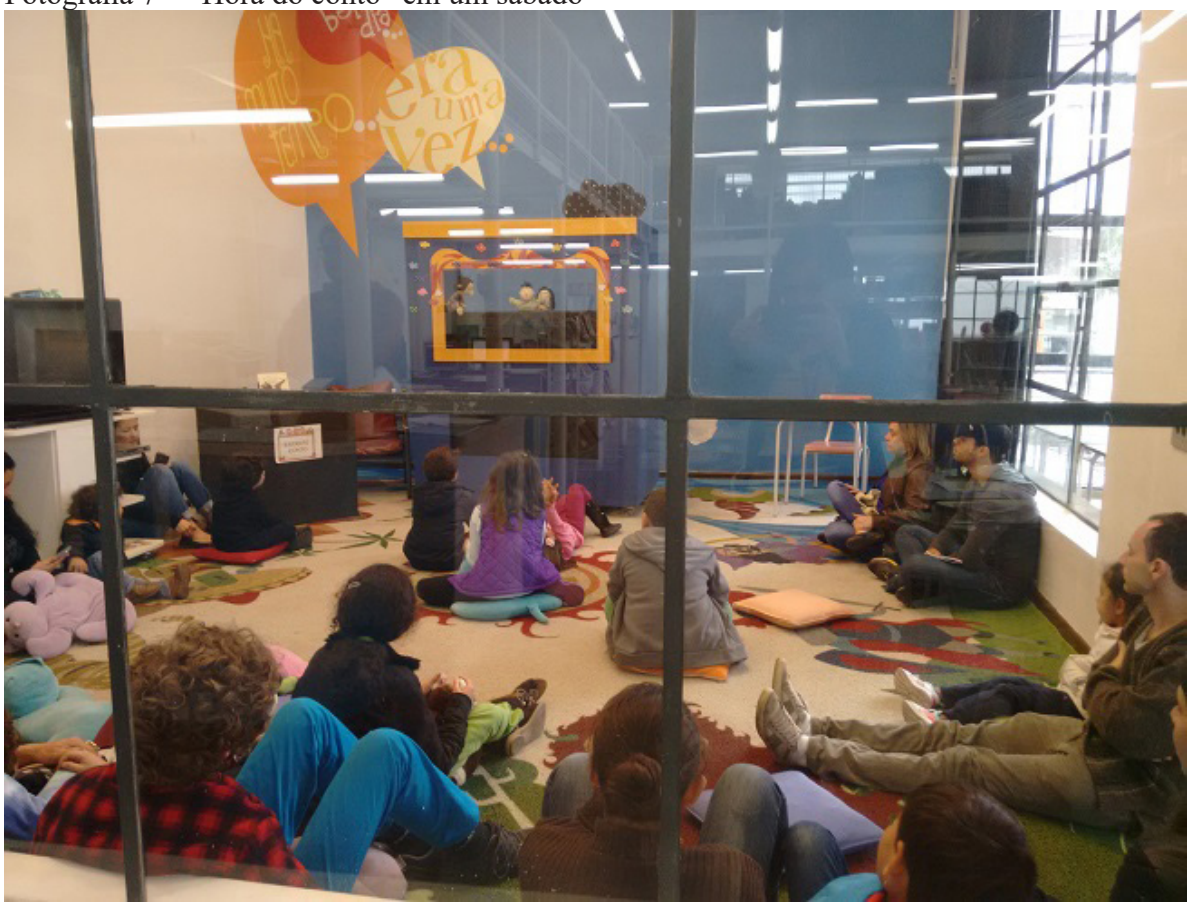

Fonte: os autores.

As contações assistidas foram realizadas nas modalidades de teatro de sombras e de fantoches. De acordo com a história, houveram algumas adaptações, 
como no cenário da história $O$ comedor de nuvens, no qual os contadores fizeram a representação do céu, e na história Quem tem medo de bruxa?, em que eles construíram a vassoura da bruxa a partir de um pedaço de graveto. Observamos seis momentos da "Hora do conto" na BPP. Neles foram contadas três histórias diferentes: Ari areia: um grãozinho apaixonado e as duas histórias já citadas. As contações se repetiram porque, geralmente, é trabalhado o mesmo livro durante uma semana. Todas as histórias observadas tiveram duração máxima de 15 minutos de apresentação.

Diante desse contexto, entendemos que uma arte linguística, tendo como público privilegiado as crianças, não deve ser sempre silenciosa. Os momentos de partilha daquilo que fora individual são necessários, pois provocam novos olhares, novas leituras, novas apropriações. Se é assim para os adultos, por que seria diferente para as crianças? Abramovich (1995, p. 18) descreve que: "Contar histórias é uma arte... e tão linda!!! É ela que equilibra o que é ouvido com o que é sentido, e por isso não é nem remotamente declamação ou teatro... Ela é o uso simples e harmônico da voz." Corroborando a autora, Busatto (2001, p. 74) demarca bem a relação entre o teatro e a narrativa na contação de histórias.

O teatro apresenta ações, a narrativa as descreve. É evidente que durante as contações de histórias podemos nos apropriar de alguns elementos oferecidos pela linguagem teatral. Mas até onde essa apropriação é permitida, para que o contador de histórias mantenha as suas características? Até o limite que preserve ao ouvinte a possibilidade de imaginar os personagens e as suas ações, sem determinar através de um corpo ou de uma voz como é aquele personagem, e qual é a ação que ele está executando.

Essa relação fica ainda mais evidente quando buscamos compreender a formação e a identidade dos contadores, que são, em sua maioria, atores e licenciados em Artes Cênicas. Assim, o uso da modalidade teatral como recurso torna-se efetiva para o grupo, que, utilizando os fantoches, privilegia muito mais a narrativa, além de atrair a atenção das crianças.

Segundo Silva (1990 p. 46), cada “[...] apresentação tem vantagens especiais, corresponde a determinados objetivos, e saber o recurso é fundamental. As formas de apresentação devem ser alternadas e definidas dependendo do local e das circunstâncias [...]" Nas observações realizadas na seção infantil da BPP houve uma pequena variação metodológica da hora do conto. Apesar de, na maioria das vezes, ser utilizado o teatro de fantoches, houve uma semana dedicada ao teatro de sombras, conforme apresentamos na Fotografia 8. 
Fotografia 8 - "Hora do conto" com teatro de sombras

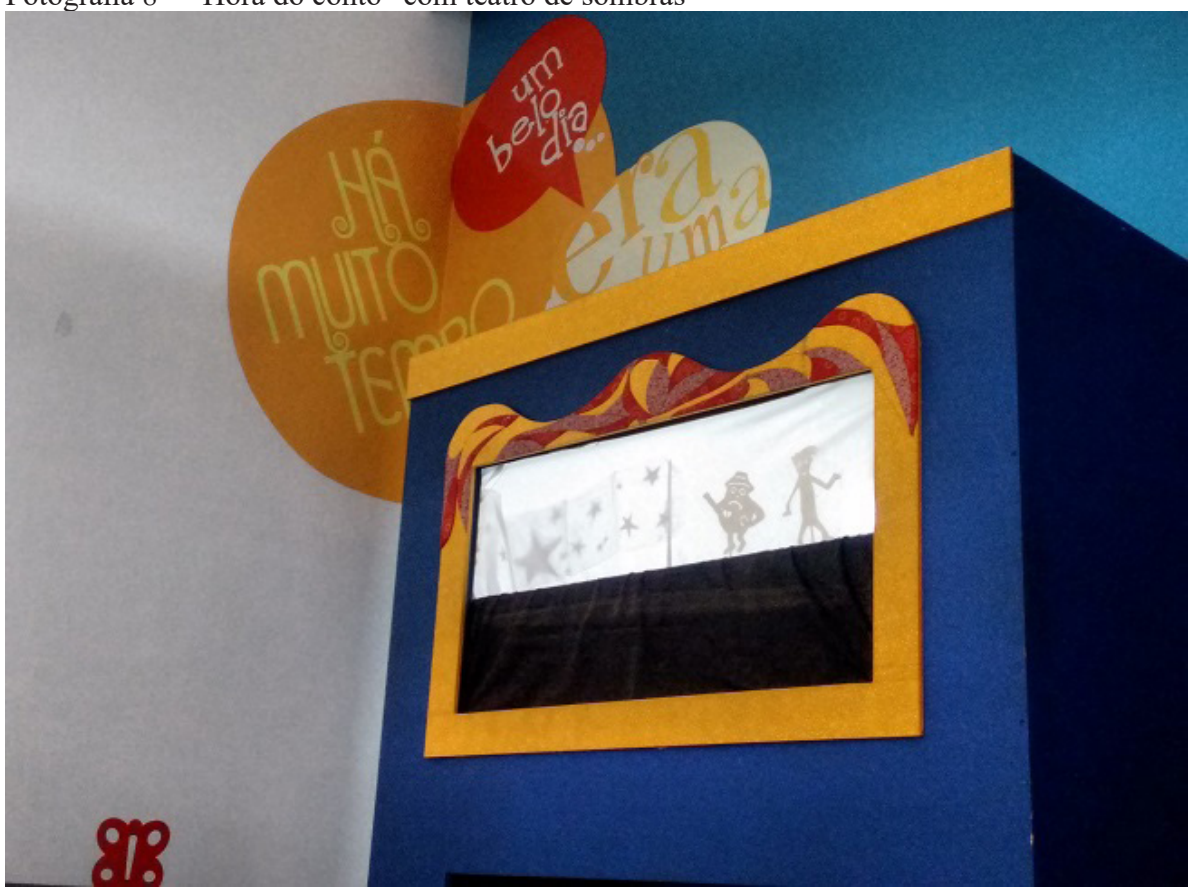

Fonte: os autores.

Outro elemento que se destacou nesta pesquisa foi o planejamento. Como aponta Carvalho (2005, p. 54): "Planejar a mediação de leitura é programar, com antecedência, a ação que se pretende desenvolver, providenciando os meios para sua realização [...]" É perceptível a existência do planejamento para a "Hora do Conto" na BPP e do domínio do texto por parte dos contadores, pois a conexão entre eles aparece em todos os momentos, inclusive naqueles em que há a necessidade de ajustar o plano para superar os imprevistos.

A faixa etária também é uma preocupação. Há interesses comuns a cada fase da infância, e é importante atentar para isso. De acordo com Silva (1990, p. 14), dos “[...] vários indicadores que nos orientam na seleção da história destaca-se o conhecimento dos interesses predominantes de cada faixa etária."

Nesse sentido, foi observada que a idade comum dos frequentadores da "Hora do conto" varia entre 0 e 14 anos. Vimos a presença de alguns bebês, crianças menores de cinco anos e maiores de 10 anos de idade, mas o fluxo de crianças entre cinco e 10 anos é superior ao das outras. Assim, observando também a recepção das histórias selecionadas, percebemos que estas possuíam linguagem simples, de fácil 
compreensão por todas as idades ali representadas, fazendo com que o texto cativasse a atenção dos leitores/ouvintes.

Em relação à narrativa, fica evidente o começo, o ápice e o fim da história, o que significa uma boa adaptação dos contadores, pois as histórias, quando transmitidas oralmente para um público com idade diversa, devem ser mais curtas e objetivas, com o cuidado de não mudar o sentido do que o autor escreveu. Essa adaptação da história tem interpretações diferentes por parte dos estudiosos do tema. Dessa forma, é relevante, segundo Carvalho (2005, p. 50), “[...] que se leia a história exatamente como está escrita, que ela não seja contada com as próprias palavras do mediador, pois queremos transmitir o texto em sua forma narrativa. Ao ler exatamente como está escrito garante-se a permanência da história."

No entanto, quando falamos em contação de histórias, principalmente pela modalidade de teatro de fantoches, há uma transposição do texto pelos contadores, às vezes até uma adaptação. Segundo Silva (1990, p. 13), "Nem toda história vem no livro pronta para ser contada. A linguagem escrita, por mais simples e acessível, ainda requer a adaptação verbal que facilite sua compreensão e a torne mais dinâmica, mais comunicativa."

Ainda há outro aspecto a ser considerado na transferência do livro para a contação da história que são as ilustrações. Para Busatto (2001, p. 53), “[...] narrar significa também a capacidade de traduzir oralmente as imagens contidas no texto [...]" Há livros em que a ilustração fala muito com o leitor, por isso é importante, quando se conta uma história sem a exposição das páginas do livro, a consideração também da importância da ilustração para transferir as emoções das personagens em determinados momentos.

De acordo com a autora, a hora do conto possui uma função elementar: "Sugerir: eis um trunfo do conto. Ele não entrega nada pronto à criança [...]" (BUSATTO, 2001, p. 53). Acredita-se que esse ponto é o mais relevante na hora do conto, sugerir, independentemente do modo como um contador se apropria da história e dos mecanismos que utiliza para repassá-la é de extrema relevância que a interpretação na hora do conto seja um momento pessoal e reflexivo para cada ouvinte em suas especificidades e, assim, proporcione uma prática de leitura em que o leitor interaja, de algum modo, com o texto, desenvolvendo sua potencialidade de ler nas múltiplas formas que a leitura se apresentar a ele.

\section{CONSIDERAÇÕES FINAIS}

Neste artigo buscou-se discutir como a literatura vem sendo trabalhada na seção infantil da BPP, especialmente na "Hora do conto". Para compreender a prática 
de contação de histórias na BPP e sua contribuição na formação do leitor, foi necessário presenciar esse momento algumas vezes, o que nos proporcionou subsídios fundamentais para a compreensão do objeto deste trabalho. Além disso, foi fundamental entrelaçar os dados resultantes das observações com os registros fotográficos, os quais serviram para voltar muitas vezes aos detalhes que nos escaparam no momento da pesquisa em campo e analisar mais detidamente certos aspectos do trabalho. Dessa maneira, alguns pontos deste artigo poderão ser retomados em estudos futuros.

Primeiramente, sugere-se repensar a questão do espaço e da disposição de recursos destinados especificamente ao gosto infantil que, fomentados por práticas de estímulo à leitura, acabam tornando-se espaços de encontros culturais, provocando o interesse pela leitura, esta que, por se realizar no âmbito público, coloca as crianças em contato direto com o universo literário. Esse primeiro contato é fundamental para a criação de um gosto, de uma estética, de um perfil de leitor, o qual é exposto desde cedo a uma multiplicidade de linguagens.

Outro ponto bastante discutido aqui foi a identidade e a produção de sentidos e sensibilidades individuais a cada criança. Despertar sentidos, emoções, percepções e críticas fazem parte das habilidades de leitura que são construídas ao longo da vida, em seus inúmeros modos de fazer.

A "Hora do Conto", nosso objeto de estudo, trouxe vários pontos importantes de discussão em relação à leitura. Percebemos que esse recurso da seção infantil da BPP pode contribuir para a formação do leitor literário a partir do uso qualitativo de diversas características, como: o planejamento, a adaptação verbal, os recursos onomatopeicos e as repetições, mas, principalmente, pelo fato do enfoque na imaginação e/ou fantasia infantil.

Nesse seguimento, presenciar um adulto leitor torna-se relevante para as crianças, pois elas relacionam um momento prazeroso de ouvir uma narrativa ou apreciar um teatro com a leitura literária individual, e isso é muito efetivo no caso da seção infantil da BPP. Nesse cenário, os momentos de partilha, a liberdade de escolha das crianças e a mediação da leitura pela "Hora do conto" foram pontos que se apresentaram como um forte estímulo para o interesse delas em retornar à biblioteca para mergulhar no mundo da leitura.

A interação com adultos leitores permitirá à criança criar um referencial próprio, o qual poderá servir como inspiração em sua própria vida. Dominar os códigos de leitura e escrita, a partir daí, será uma tarefa menos traumática. Primeiro, porque há uma intimidade com esse código e, segundo, porque essa criança percebe, ainda que intuitivamente, que esse domínio a conduz para um universo novo a ser explorado. 
Portanto, o presente estudo reafirmou a possibilidade de instituir bibliotecas infantis vivas, independentemente se são escolares ou públicas, que busquem o benefício individual de cada criança. Na seção infantil da BPP, a leitura se constrói como prática cultural, objeto lúdico, produtora de sentidos e sensibilidades próprios de cada criança leitora. Da mesma forma, um olhar mais atento para esse universo chama a atenção para as múltiplas formas de educar e formar do nosso tempo e de nossa sociedade. Há, no entanto, muito ainda para ser investigado em relação aos modos de ler, aos materiais e às práticas de leitura, mas, sobretudo, há muito para se compreender sobre as apropriações que se formam dessa experiência leitora e os significados que esses sujeitos atribuem ao ato de ler. O foco privilegiado na escola tem contribuído para discutirmos problemas, erros e acertos que ocorrem nesse espaço, mas tem deixado passar contextos educacionais não formais que carecem de maior investimento de pesquisa por se revelarem também constitutivos de nossa história educacional.

\section{REFERÊNCIAS}

ABRAMOVICH, F. Literatura Infantil: gostosuras e bobices. São Paulo: Scipione, 1995.

ARROYO, M. A. infância interroga a Pedagogia. In: SARMENTO, M.; GOUVEA, M. C. S. de (Org.). Estudos da Infância: educação e práticas sociais. Petrópolis: Vozes, 2008. p. 119-140.

BIBLIOTECA PÚBLICA DO PARANÁ. Histórico. Disponível em: < http://www. bpp.pr.gov.br/modules/conteudo/conteudo.php?conteudo=3>. Acesso em: 19 out. 2017.

BRASIL. Parâmetros curriculares nacionais: língua portuguesa. Brasília, DF: Secretaria de Educação Fundamental, 1998.

BUSATTO, C. Contar e encantar: pequenos segredos da narrativa. Petrópolis: Vozes, 2001.

CARVALHO, C. et al. Biblioteca viva: fazendo história com livros e leituras. São Paulo: Fundação ABRINQ; Citigroup, 2005.

CHARTIER, R. Cultura escrita, literatura e história: conversas de Roger Chartier com Carlos Aguirre Anaya, Jesús Anaya Rosique, Daniel Goldin e Antonio Saborit. Porto Alegre: Artmed, 2001.

CHARTIER, R. O mundo como representação. Revista Annales, n. 6, p. 1505-1520, nov./dez. 1989. 
CURITIBA. Secretaria Municipal de Educação. Diretrizes Curriculares Municipais de Educação Infantil. Objetivos de aprendizagem: uma discussão permanente. Curitiba, 2012.

GIL, A. C. Métodos e técnicas de pesquisa social. São Paulo: Atlas, 2008.

LUDKE, M; ANDRÉ, M. E. D. A. Pesquisa em educação: abordagens qualitativas. São Paulo: EPU, 1986.

MARANGON, C. Um centro de recursos em sintonia com a sala de aula. Revista Pátio, Porto Alegre, n. 24, ano 8, p. 44-46, jul./set. 2010.

MILANESI, L. A. Outra biblioteca pública: uma profecia de Mário de Andrade. Revista da Biblioteca Mário de Andrade, São Paulo, v. 51, p. 59-64, jan./dez. 1993.

MONTEIRO, M. Z. Bibliotecas Públicas: práticas, histórico e perspectivas. In: Coordenadoria do Sistema Municipal (Org.). Bibliotecas Públicas: ações, processos e perspectivas. São Paulo: CSMB, 2012.

ROJAS, A. K. Uma história com final feliz. Será? Revista Pátio, Porto Alegre, n. 24, ano 8, p. 3, jul./set. 2010.

SILVA, R. J da. Leitura, biblioteca e política de formação de leitores no Brasil. Revista BJIS, Marília, v. 3, n. 2, p. 75-92, jul./dez. 2009.

SILVA, M. B. C. Contar histórias: uma arte sem idade. São Paulo: Ática, 1990.

SILVA, M. C. Infância e Literatura. Rio de Janeiro: Ed. UERJ, 2010.

SILVA, M. C. Leitura, pesquisa e ensino. Rio de Janeiro: Ed. UERJ, 2013.

ZILBERMAN, R. A literatura infantil na escola. São Paulo: Global, 2003.

Recebido em: 22 de abril de 2017

Aceito em: 30 de outubro de 2017

Endereço para correspondência: Rua Imaculada Conceição, 1155, Prado Velho, 81611-970, Curitiba, Paraná, Brasil; evelynorlando@gmail.com 
